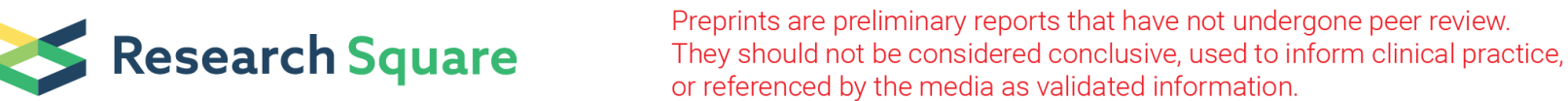

\section{Definition and Validation of a Risk-Stratification Model for Probable or Proven COVID-19 Patients in Emergency Departments: The Revised HOME-CoV Score.}

\section{Douillet Delphine ( $\nabla$ delphinedouillet@gmail.com )}

Centre Hospitalier Universitaire de Angers

Riou Jérémie

Centre Hospitalier Universitaire de Angers

Morin Francois

Centre Hospitalier Universitaire de Angers

Mahieu Rafaël

Centre Hospitalier Universitaire de Angers

Chauvin Anthony

Lariboisière Hospital

Gennai Stéphane

Centre Hospitalier Universitaire De Reims

Ferrant Lionel

Cliniques Universitaires Saint-Luc

Lopez Raphaëlle

Sart Tilman University Hospital, Liège

Sebbane Mustapha

University Hospital of Montpellier

Plantefeve Gaëtan

Centre Hospitalier Victor Dupouy

Brice Christian

ch saint brieuc

Cayeux Coralie

$\mathrm{CH}$ remiremont

Moumneh Thomas

Centre Hospitalier Universitaire de Angers

Savary Dominique

Centre Hospitalier Universitaire de Angers

Penaloza Andrea

Cliniques Universitaires Saint-Luc 


\section{Roy Pierre-Marie}

Centre Hospitalier Universitaire de Angers

\section{Research Article}

Keywords: COVID-19, risk stratification, prognostic tool, score validation, rule-based decision-making

Posted Date: February 26th, 2021

DOI: https://doi.org/10.21203/rs.3.rs-201491/v1

License: (c) (1) This work is licensed under a Creative Commons Attribution 4.0 International License. Read Full License 


\section{Abstract}

The HOME-CoV rule is a list of clinical criteria defined by experts' consensus, qualifying patients with probable or proven COVID-19 for home treatment when negative. The aims were to define and validate a revised HOME-CoV score, optimizing the original rule. Definition of the revised HOME-CoV score using logistic regression in a prospective multicenter cohort and validation in another cohort of patients who presented to the emergency department with proven or probable COVID-19. The main outcome was noninvasive or invasive ventilation or all-cause death within the 7 days following inclusion. Two threshold values were defined using a sensitivity of $>0.9$ and a specificity of $>0.9$ to identify low-risk patients and high-risk patients, respectively. The revised HOME-CoV score included seven clinical criteria. In the definition cohort ( $n=1696)$, the AUC was 87.6 ( $95 \% \mathrm{Cl} 84.7$ to 90.6). The cutoffs to define low-risk and high-risk patients were $<2$ and $>3$, respectively. In the validation cohort $(n=1304)$, the AUC was 85.8 ( $95 \%$ $\mathrm{Cl} 80.6$ to 91.0$)$ and 85.5 (95\% $\mathrm{Cl} 76.8$ to 94.1$)$ in the subgroup of patients with positive RT-PCR for SARSCoV2. A score of $<2$ qualified $73 \%$ of patients as low risk with a sensitivity of $0.84(0.66-0.95)$ and a negative predictive value of 0.99 (0.99-1.00). The revised HOME-CoV score compared favorably with the original rule and other models. The revised HOME-CoV score may allow accurate risk stratification and safely qualify for home treatment, a significant proportion of patients with probable or proven COVID-19.

\section{Introduction}

The current pandemic of the novel 2019 coronavirus disease (COVID-19) has led to a substantial increase in the demands on conventional, acute and critical care services around the world and we continue to see a succession of waves ${ }^{1}$. The clinical spectrum of COVID-19 is broad, ranging from simple rhinitis to major pulmonary disease and death ${ }^{2,3}$. Mild or moderate infection corresponds to $80 \%$ of the COVID-19 population but approximately $2-4 \%$ of the patients require mechanical ventilation for Acute Respiratory Distress Syndrome (ARDS) ${ }^{4-6}$. For many of them, the deterioration is rapid after an initial period of relatively mild symptoms, emphasizing the need for early risk stratification. A reliable risk assessment model is therefore required to standardize practices and guide frontline physicians in the decision to hospitalize or to manage at home mild or intermediate COVID-19 patients.

\section{Importance}

In this pandemic context, rationalizing hospital care is a major health issue to empower healthcare providers caring for patients at a high risk of adverse outcomes. Several clinical and biological features have been identified as mortality independent risk factors in COVID-19 ${ }^{7-9}$. Risk assessment models and triaging tools have been proposed, especially to refer COVID-19 patients to intensive care units. However, a recent living systematic review of COVID-19 conducted in collaboration with the Cochrane Prognosis Methods Group, found that all prognosis scores have a high risk of bias owing to poor reporting and poor methodological conduct enabling their recommendation for use in current practice ${ }^{10}$. The authors recommend following methodological guidance in order to avoid the use of unreliable and possibly 
harmful models in guiding clinical decision-making, and in particular, i) to build prediction models based on previous literature and expert consensus rather selecting predictors in a purely data driven way, ii) to develop and validate the model on a representative dataset of the target population in which it serves a clinical need, and iii) to currently focus on validating and updating promising available models.

Using a Delphi method with 51 experts, we defined the "Hospitalization or Outpatient ManagEment of patients with SARS-CoV-2 infection" (HOME-CoV) rule. It contained 8 clinical criteria easily assessable at ED presentation (Table 1) ${ }^{11}$. The performances of the HOME-CoV rule in defining a subgroup of patients with proven or probable COVID-19 who can be safely managed at home were recently confirmed in a prospective implementation before and after study: the HOME-CoV trial (NCT04338841, submitted).

\section{Goals of this investigation}

The global aim of the present study was to optimize the HOME-CoV rule in defining and validating an updated version: the revised HOME-CoV score. The objective was to obtain a parsimonious and easy to apply score with 3 risk levels: low-risk patients who could be safely managed at home, intermediate-risk patients who may require hospitalization and high-risk patients who may benefit from intensive care.

\section{Results}

\section{Source of data}

A total of 3000 patients with confirmed or probable SARS-CoV-2 were included, 1696 patients in the training cohort and 1304 in the validation cohort. Respectively, 65/1696 (3.8\%) and 22/1304 (1.7\%) patients had an adverse evolution in the training and the validation cohorts. Patients characteristics are presented in Table 2.

\section{HOME-CoV Score Revision}

The revised HOME-CoV score included 7 criteria (Table 3). The values of each criterion are mentioned in Table S2. The criterion "age over 65 years" was an independent factor of an adverse evolution within 7 days and its addition to the criteria of the original HOME-CoV score improved the performances of the score. Conversely, in the backward selection process, the criteria "Systolic blood pressure $<90 \mathrm{mmHg}$ ", "Heart rate $\geq 120 \mathrm{bpm}$ " and "Severe comorbidity" were non-discriminatory and could be excluded without decreasing the revised score performances. The criteria "Ability to talk without breathing $<8$ seconds" was a co-variable that positively impacting the model prediction. In the training cohort, the AUC of the revised HOME-CoV score was 87.6 (95\% Cl 84.7 to 90.6), a C-Index of 86.6 and the Brier score was of 0.045 (Table 4). The AUC of the original HOME-CoV score was 80.9 (95\% Cl 76.3 to 85.6$)$, a C-Index of 80.5 and the Brier score was of 0.048 .

The highest score value achieving a sensitivity of at least 0.90 was $<2$ for the low-risk patients and for defining high-risk patients, the lowest score value achieving a specificity of at least 0.90 was $>3$ (Table 5). 
In the subgroup of patients with confirmed SARS-CoV 2 infection ( $\mathrm{n}=364$ patients), the revised HOMECoV score had an AUC of 83.7 (95\% Cl 78.6 to 88.7), a C-Index of 83.2 and a Brier score of 0.11 (Table 4).

\section{Revised-HOME-CoV Score Validation}

In the validation cohort, the AUC of the revised HOME-CoV score was 85.8 (95\% $\mathrm{Cl} 80.6$ to 90.9), the Brier score was 0.019 and the C-Index was 85.71 to predict an adverse evolution within the 7 days (Table 4). The calibration slope was 0.974 (close to 1 ) and the calibration intercept was -0.76 suggesting an overestimation (Fig. 1).

Using a score value of $<2$ as cut-off, 949/1304 (72.8\%) were qualified as low-risk patients and among them 5 had an adverse evolution (with a sensitivity of $0.84(0.66-0.95)$ and a negative predictive value of $0.99(0.99-1.00))$ and $86 / 1304(6.6 \%)$ patients had a score of $>3$ and were qualified as high-risk patients. Among them 12 had an adverse evolution with a specificity of $0.94(0.93-0.96)$ and a positive predictive value of $0.14(0.07-0.23)$ ) (Table 5$)$.

In the subgroup of patients with confirmed SARS-CoV 2 infection $(n=183$ patients), the revised HOMECoV score had an AUC of 85.5 (95\% Cl 76.8 to 94.1) and a Brier score of 0.047 (Table 4). In this subgroup, 114/183 (62.3\%) patients were qualified as low-risk patients and among them 1 had an adverse evolution (with a sensitivity of 0.91 (0.59-1.00) and a negative predictive value of $0.99(0.95-1.00)) ; 11 / 183(6.0 \%)$ patients were qualified as high-risk patients, and among them 3 had an adverse evolution (with a specificity of $0.96(0.92-0.98)$ and a positive predictive value of $0.13(0.05-0.32))$.

\section{Comparison of the clinical risk assessment models}

The predictive performances within the 7 days of the different scores are summarized in Table 4 and Table S3. The revised HOME-CoV score exhibited the highest AUC in both cohorts. Its AUC was significantly higher than that of the qSOFA, CURB65 and SMART-COP scores.

In the validation cohort, the original HOME-CoV rule qualified 627/1304 (48.1\%) patients as low-risk (all criteria negative) and among them 1 had an adverse evolution (sensibility of $0.95(0.92-0.98)$ and a negative predictive value of 0.99 (0.97-1.00).

\section{Complementary analyses}

\section{Time-dependent prediction}

The AUC of the revised HOME-CoV score slightly decreased from Day 2 to Day 7 and was stable after Day 7: 85.8 (80.1-91.0) at Day 28 (Table 4, Figure S1).

\section{Prediction of patients requiring intubation or dying within the 7 days}

Results were similar regarding the rate of patients requiring intubation or who died within the 7 days (WHO-OSCl $\geq 6$ ) with an AUC of the revised HOME-CoV to 86.7 (95\%Cl 84.6 to 91.8) (Table S4). 


\section{Discussion}

The revised HOME-CoV score included 7 clinical criteria easy to assess upon patient's presentation in the emergency department. It exhibited good and stable over-time performances in predicting an adverse evolution in patients with suspected COVID-19 and in patients with confirmed COVID-19, outperforming the other risk models for COVID-19. Three levels of risk have been established. Low-risk patients, eligible for home treatment, accounted for almost three quarters of the study population and less than $1 \%$ will require intensive care within the 28-day follow-up.

The definition of the revised HOME-CoV score was made according to recent recommendations ${ }^{10,11}$. The criteria were firstly chosen by expert consensus and were completed by the clinical items present in the other scores ${ }^{10,11}$. A logistic regression model and the Akaïke Information Criterion were used to choose the most parsimonious model rather than to identify the criteria of interest. In this process, three criteria of the original rule were excluded (heart rate, blood pressure and severe comorbidity), and one additional criterion was included in the revised HOME-CoV score (age $>65$ years). The age had not been retained by the experts in the original HOME-CoV rule because this rule was performed as a checklist, qualifying patients with probable or proven COVID-19 for home treatment when all criteria were negative. The experts participating to the Delphi consensus did not consider that advanced age, as a standalone criterion, preclude home treatment. The revised and somewhat simplified HOME-CoV score exhibits better performances in risk characterization of adverse evolution than the original version. This result emphasizes that the prognosis of COVID-19 is correlated to respiratory lesions rather than to systemic sepsis with hemodynamic instability ${ }^{12}$.To facilitate its implementation in ED current practice, biological variables and imaging data were not considered in the revised HOME-CoV score. The clinical variables are easy to assess upon presentation at the ED and enable rapid home discharge of low-risk patients. Moreover, the limited number of items makes the score easily memorable.

Many other risk-assessment scores have been proposed for COVID-19 patients ${ }^{9,13-19}$. Most of them are highly susceptible of bias, incorporate biological or imaging data and/or are complex requiring computational tools such as the recently proposed $4 \mathrm{C}$ mortality score and COVID-19 GRAM ${ }^{15,16}$. Furthermore, their performances do not appear to be better than those of the revised HOME-CoV score 15,16. In our study, the AUC of the CURB65 (including uremia) and of the SMART-COP (including multilobar involvement on chest-ray or CT scan) were significantly lower than the AUC of the revised HOMECoV score. Importantly, to our knowledge, all previous models were established in a population of hospitalized COVID-19 patients and could not serve in identifying ED patients who can be safely discharged home. The revised HOME-CoV rule was defined and validated in two cohorts of consecutive ED patients with highly suspected or proven non-severe COVID-19. Therefore, these datasets represent the target population that may benefit from its implementation as a helpful decision-making tool ${ }^{10}$. Moreover, the same positive performances were observed in the overall population and in the subgroup of patients with a positive RT-PCR for SARS-CoV2. This reinforces the validity of the score and its usability in EDs where access to RT-PCR for SARS-CoV2 is limited and/or where obtaining the results requires several 
hours ${ }^{20}$. A revised HOME-CoV score below 2 allows rapid and safe qualification by the emergency physicians of $3 / 4$ of patients with probable or confirmed COVID-19 for home treatment. As compared to the original rule, the revised $\mathrm{HOME}-\mathrm{CoV}$ score may significantly increase the rate of patients managed at home without increasing their risk of death or to requiring intensive care. It could also be used by other frontline physicians such as general practitioners or geriatricians and efficiently participate in mitigating the burden on the healthcare system.

This study has several strengths. Analyses and results are based on a multicenter study with a large number of participating centers and patients and prospective data collection. Two separate cohorts were used to review and validate the score. We used a clinical and consensual main judgment outcome: the ordinal scale for clinical improvement of COVID-19 from the WHO. This scale, and especially for the last stages, seems less dependent on physician's gestalt and hospital caseload than ICU admission or oxygen requirement. The methodology used follows the most recently published recommendations and the TRIPOD reporting guidelines ${ }^{10}$.

It also has some limitations. The rate of patients who had an adverse evolution was low, limiting the accuracy of the measurements. Both cohorts came from the same centers. The revised HOME-CoV score needs to be formally validated in a prospective implementation outcome study.

In conclusion, the revised HOME-CoV score allows for accurate risk-stratification of patients presented to emergency departments with proven or probable COVID-19. Future studies may evaluate its usefulness to help frontline physicians in decision-making.

\section{Methods}

\section{Study design}

We performed a retrospective analysis of a prospective multicenter before and after implementation trial aimed at validating the original HOME-CoV rule (NCT04338841, submitted).

The first step was the definition of the revised HOME-CoV score to enhance the predictive performances of the original HOME-CoV rule through the inclusion of clinical predictors identified in other models and the exclusion of poor informative variables. The second step was the external validation of the revised HOME-CoV score in an independent cohort. The third step was the comparison of the performances of the revised and the original HOME-CoV score compared to those of other assessment models proposed for risk stratification of COVID-19 patients: qCSI, qSOFA, CURB65, CRB65 and SMART-COP 13,21-23 (Table 1). We adhered to the Transparent Reporting of a multivariable prediction model for Individual Prognosis Or Diagnosis (TRIPOD) checklist (Appendix 1).

\section{Source of data}


We used two distinct and independent phases of a prospective study ( $\mathrm{n}=3000$ patients). This study was a quasi-experimental before and after prospective multicenter trial, performed in 34 Emergency Departments from in France (31), Principality of Monaco (1) and Belgium (2) from April 9 to May 11, 2020. Patients were eligible for inclusion if they provided informed consent, were at least 18 years old, had symptomatic COVID-19 confirmed by a positive SARS-CoV-2 Reverse Transcriptase-Polymerase Chain Reaction (RT-PCR), or had typical symptoms of COVID-19 and the COVID-19 was the most likely hypothesis for the physician in charge of the patient in the ED, and had provided informed consent. Only mild and moderate cases of COVID-19 were included. Patients were excluded if the main diagnostic hypothesis in the emergency room was not a SARS-CoV-2 infection but another differential diagnosis, if they required care in an ICU or a resuscitation unit, if a limitation decision of active therapies was made, and if the follow-up at 28 days was not possible. Patients characteristics and clinical data were collected prospectively at the ED presentation (Table 2). Biological or imaging examinations were not required. Patients were followed-up at Day 7 and Day 28 by phone and their clinical status according to the Ordinal Scale for Clinical Improvement for COVID-19 patients from the World Health Organization was recorded (WHO-OSCI) (Table S1) ${ }^{24}$. The date of each change in WHO-OSCl status was also recorded to allow analysis over time.

\section{Outcome}

The main outcome was an adverse evolution within the 7 days after ED presentation. It was defined, according to the World Health Organization, as a hospitalized patient with severe disease, under noninvasive ventilation or high-flow nasal oxygen therapy (stage 5), requiring intubation and invasive ventilation (stage 6), and/or additional organ support (stage 7) or who died whatever the cause (stage 8) (Table S1) ${ }^{24}$.

\section{HOME-CoV Score Revision}

To define the revised HOME-CoV score, we assessed if the inclusion of clinical variables included in other models suggested for risk stratification of COVID-19 patients (Table 1), would improve the performances of the original HOME-CoV rule, and, conversely, if the exclusion of clinical variables of the original rule would decrease the performances of the revised HOME-CoV score. In order to facilitate the implementation of the revised HOME-CoV score in current practice of emergency and primary care physicians, we did not consider the inclusion of biological variables (uremia, $\mathrm{pH}$, albuminemia). Only one clinical variable, an age of $>65$ years, included in the CRB65 and CURB65 was found for this purpose ${ }^{11}$.

A logistic regression model was performed to assess the discriminant value of each criterion of the original rule and of an age over 65 years regarding adverse evolution ( $\mathrm{WHO}-\mathrm{OSCl} \geq 5$ ). In order to choose the most parsimonious model, a selection of variables allowing the optimization of the Akaïke Information Criterion (AIC) was carried out in a manual backward selection process. All significant variables, as well as the non-significant variables that interact with the other items and provide the best AIC were retained. The absence of multicollinearity between predictors was checked using the variance 
inflation factor. We anticipated 3 levels of risk prognosis to identify a low-risk subgroup of patients who could be safely treated at home, an intermediate-risk subgroup who require hospitalization and a high-risk subgroup of patients who may require intensive care. For defining low-risk patients, we chose the highest score value achieving a sensitivity of at least 0.90 and for defining high-risk patients, we chose the lowest score value achieving a specificity of at least 0.90 .

\section{Revised-HOME-CoV Score Validation}

The accuracy of the score was assessed by calculating the Receiver Operating Characteristic (ROC) curve and analysing the Area Under the Curve (AUC). The AUC confidence interval was computed with the Delong-Delong method. An AUC of $\geq 0.8$ with a lower limit of the $95 \%$ confidence interval $(95 \% \mathrm{Cl})$ of $\geq$ 0.7 was considered as clinically relevant. The Brier score was also reported, summarizing the magnitude of error in the probability forecasts between 0.0 and 1.0 , where a perfect model has a score of 0.0 . We also calculated the $\mathrm{C}$-Index corresponding to the model discrimination. Calibration was assessed with the slope and the intercept value. Using the two predefined threshold values, the sensitivity, specificity, likelihood ratios and the negative and positive predictive values with their $95 \%$ confidence interval $(95 \% \mathrm{Cl})$ of the revised HOME-CoV score were calculated.

\section{Comparison of the clinical risk assessment models}

We used .632+ bootstrapped logistic regression to evaluate the scores' performances and their confidence intervals and to generate performance benchmarks of the different scores: original HOMECoV, revised HOME-CoV, qCSI, qSOFA and CRB65. The comparison with the CURB65 was performed in the subgroup of patients with uremia measurement at baseline and the comparison with the SMART-COP in the subgroup of patients with pulmonary imaging. In order to calculate the SMART-COP, multi-lobar lesions either on chest X-ray or CT scan were considered as a positive criterion ("multi-lobar involvement on chest X-ray"). We report $95 \%$ confidence intervals derived from the percentiles of the bootstrapped distribution.

\section{Complementary analyses}

We performed a subgroup analysis in patients with confirmed SARS-CoV-2 infection by RT-PCR.

We also performed two sensitivity analysis with the following outcomes:

(1) Adverse evolution as a function of time within the 28 days following ED presentation.

(2) Evolution to a severe disease within 7 days, defined as requiring invasive ventilation or leading to death whatever the cause (WHO-OSCl $\geq 6$ ).

\section{Statistical analysis}


Missing data were not imputed. Statistical analyses were performed using R software (version 3.5.1, RCore Team) and the following R package: pec, timeROC, and survival ${ }^{25-27 .}$

\section{Declarations}

\section{Acknowledgements}

We wish to thank the members of the HOME-CoV study group*:

- Andrianjafy H., Emergency Department, GH Nord-Essonne, Longjumeau, France.

- Baudin L., Emergency Department, CH Cholet, Cholet, France.

- Benhammouda K., Emergency Department, CH Colmar, Colmar, France.

- Bissolokele P., Emergency Department, CH Libourne, Libourne, France.

- Brice C., Emergency Department, CH Saint Brieuc, Saint Brieuc, France.

- Cayeux C., Emergency Department, CH Remiremont, Remiremont, France.

- Casalino E., Emergency Department, APHP Bichat, Paris, France.

- Casarin C., Emergency Department, Cliniques universitaires saint Luc, Bruxelles, Belgium.

- Chauvin A., Emergency Department, APHP - Hôpital Lariboisière, Paris, France.

- Choquet C. Emergency Department, APHP-Bichat, Paris, France.

- Claessens Y.-E., Emergency Department, Princess Grace Hospital, Monte Carlo, Monaco.

- Couturaud Francis, Department of Internal Medicine and Chest Diseases, EA3878 (GETBO), CIC INSERM 1412, University Hospital of Brest, European University of Occidental Brittany, Brest, France.

- Dall Acqua D., Emergency Department, CH Vichy, Vichy, France.

- Dobanton B., Emergency Department, CHU Reims, Reims, France.

- Douillet D., Emergency Department, CHU Angers, Angers, France.

- Dupriez F., Emergency Department, Cliniques universitaires saint Luc, Bruxelles, Belgium.

- Eyer X. Emergency Department, APHP - Hôpital Lariboisière, Paris, France.

- Ferrand L. Emergency Department, Cliniques universitaires saint Luc, Bruxelles, Belgium.

- Gennai S., Emergency Department, CHU Reims, Reims, France. 
- Ghuysen A., Emergency Department, CHU Liège, Belgium.

- Greau-Chauchet A. Emergency Department, CHD Vendée, Roche-sur-Yon, France.

- Joly L.-M., Emergency Department, CHU Rouen, Rouen, France.

- Karam H.-H., Emergency Department, CHU Limoges, Limoges, France.

- Layot M., Emergency Department, CHU Montpellier, France.

- Leroy A., Emergency Department, CH Troyes, Troyes, France.

- Lopez R. Emergency Department, Liège, Belgium.

- Mahieu R., Department of infectious disease, CHU Angers, Angers, France.

- Marchant N., Emergency Department, CH Alpes Lemant, Contamine sur Avre, France.

- Marjanovic N., Emergency Department, CHU Poitiers, Poitiers, France.

- Montassier E., Emergency Department, CHU Nantes, Nantes, France.

- Morin F., Emergency Department, CHU Angers, Angers, France.

- Penaloza Baeza A., Emergency Department, Cliniques universitaires saint Luc, Bruxelles, Belgium.

- Plantefeve G., Emergency Department, CH Argenteuil, Argenteuil, France.

- Roy P.-M., Emergency Department, CHU Angers, Angers, France.

- Savary D., Emergency Department, CHU Angers, Angers, France.

- Schmidt J., Emergency Department, CHU Clermont Ferrand, Clermont Ferrand, France.

- Schotte T., Emergency Department, CH Le Mans, Le Mans, France.

- Sebbane M., Emergency Department, CHU Montpellier, France.

- Soulie C., Emergency Department, CH Cholet, Cholet, France.

- Soulat L. Emergency Department, CHU Rennes, France.

- Steiner C., Emergency Department, Cliniques universitaires saint Luc, Bruxelles, Belgium.

- Thiebaud P.-C., Emergency Department, APHP-Hôpital Saint Antoine, Paris, France.

- Timsit E., Emergency Department, CHU Dijon, Dijon, France. 
- Trabattoni E., Emergency Department, APHP - Hôpital saint Joseph, Paris, France.

- Violeau M., Emergency Department, CH Niort, Niort, France.

\section{Author Contribution}

The first, second, and last author have designed the study. The first draft of the manuscript was written by the first and the last authors. All the authors contributed to the final manuscript and attest the accuracy of the data and the fidelity of the study to the protocol. The corresponding author affirms that the manuscript is an honest, accurate, and transparent account of the study being reported; that no important aspects of the study have been omitted; and that any discrepancies from the study as planned have been explained.

\section{Ethics approval and consent to participate}

The HOME-CoV study obtained approval from the Comité de Protection des Personnes Ouest IV - Nantes for France ( $N^{\circ}$ 36/20_2), from the ethical committee of the Cliniques Universitaires Saint Luc (Bruxelles) for Belgium ( $N^{\circ}$ 2020-A00831-38), and from the ethical committee Comité de Contrôle des Informations Nominatives of Monaco ( $\mathrm{N}^{\circ}$ 2020-069). This study was carried out in accordance with the Declaration of Helsinki and Good Clinical Practice guidelines.

\section{Consent for publication}

All patients had provided informed consent

\section{Availability of data and materials}

Not available

\section{Competing interest}

None of the study authors have conflicts of interest to declare.

\section{Funding}

The sponsor and the funder of the study was $\mathrm{CHU}$ Angers. The sponsor had no role in study design or data interpretation.

\section{References}

1. WHO National audit office. 2020 [Internet]. 2020 Jul 7 [cited 2020 Jul 22]; Available from: https://www.who.int/emergencies/diseases/novel-coronavirus-2019/situation-reports/.

2. Struyf, T. et al. Signs and symptoms to determine if a patient presenting in primary care or hospital outpatient settings has COVID-19 disease. Cochrane Database of Systematic Reviews. 
https://doi.org/10.1002/14651858.CD013665 (2020). ) doi

3. Ferreira, M. et al. Critically ill SARS-CoV-2-infected patients are not stratified as sepsis by the qSOFA. Ann. Intensive Care 10, 43 (2020). )

4. Guan, W. et al. Clinical Characteristics of Coronavirus Disease 2019 in China. N Engl J Med. NEJMoa2002032 ( https://doi.org/10.1056/NEJMoa2002032 (2020). ) doi

5. CDC COVID-19 Response Team. et al. Severe Outcomes Among Patients with Coronavirus Disease 2019 (COVID-19) - United States, February 12-March 16, 2020. MMWR Morb. Mortal. Wkly. Rep. 69, 343-346 (2020). )

6. Wu, Z. \& McGoogan, J. M. Characteristics of and Important Lessons From the Coronavirus Disease 2019 (COVID-19) Outbreak in China: Summary of a Report of 72314 Cases From the Chinese Center for Disease Control and Prevention. JAMA. https://doi.org/10.1001/jama.2020.2648 (2020). ) doi

7. Wang, D. et al. Clinical Characteristics of 138 Hospitalized Patients With 2019 Novel CoronavirusInfected Pneumonia in Wuhan, China. JAMA. 323, 1061 (2020). )

8. Huang, C. et al. Clinical features of patients infected with 2019 novel coronavirus in Wuhan, China. The Lancet. 395, 497-506 (2020). )

9. Zhao, Z. et al. Prediction model and risk scores of ICU admission and mortality in COVID-19. PLoS ONE. 15, e0236618 ( (2020). )

10. Wynants, L. et al. Prediction models for diagnosis and prognosis of covid-19: systematic review and critical appraisal. BMJ m1328 (2020) doi:10.1136/bmj.m1328.

11. Douillet, D. et al. Outpatient management or hospitalization of patients with proven or suspected SARS-CoV-2 infection: the HOME-CoV rule. Intern Emerg Med. https://doi.org/10.1007/s11739-02002483-0 (2020). ) doi

12. Sy, B. \& Jy, H. Characteristics and Outcomes of 21 Critically III Patients With COVID-19 in Washington State.3(2020).

13. Haimovich, A. et al. Development and validation of the quick COVID-19 severity index (qCSI): a prognostic tool for early clinical decompensation. Annals of Emergency Medicine. S0196064420305886 ( https://doi.org/10.1016/j.annemergmed.2020.07.022 (2020). ) doi

14. Maves, R. C. et al. Triage of Scarce Critical Care Resources in COVID-19 An Implementation Guide for Regional Allocation. Chest. 158, 212-225 (2020). )

15. Liang, W. et al. Development and Validation of a Clinical Risk Score to Predict the Occurrence of Critical Illness in Hospitalized Patients With COVID-19.9(2020).

16. Knight, S. R. et al. Risk stratification of patients admitted to hospital with covid-19 using the ISARIC WHO Clinical Characterisation Protocol: development and validation of the $4 \mathrm{C}$ Mortality Score. BMJ m3339 (2020) doi:10.1136/bmj.m3339.

17. Holten, A. R., Nore, K. G., Tveiten, C. E. V. W. K., Olasveengen, T. M. \& Tonby, K. Predicting severe COVID-19 in the Emergency Department. Resuscitation Plus. 4, 100042 (2020). ) 
18. Ji, D. et al. Prediction for Progression Risk in Patients With COVID-19 Pneumonia: The CALL Score. Clin Infect Dis. 71, 1393-1399 (2020). )

19. Jehi, L. et al. Development and validation of a model for individualized prediction of hospitalization risk in 4,536 patients with COVID-19. PLoS ONE. 15, e0237419 ( (2020). )

20. Seidu, A. A., Hagan, J. E., Ameyaw, E. K., Ahinkorah, B. O. \& Schack, T. The role of testing in the fight against COVID-19: Current happenings in Africa and the way forward. International Journal of Infectious Diseases. 98, 237-240 (2020). )

21. Ferreira, F. L. Serial Evaluation of the SOFA Score to Predict Outcome in Critically III Patients. JAMA. 286, 1754 (2001). )

22. Lim, W. S. Defining community acquired pneumonia severity on presentation to hospital: an international derivation and validation study. Thorax. 58, 377-382 (2003). )

23. Charles, P. G. P. et al. SMART-COP: A Tool for Predicting the Need for Intensive Respiratory or Vasopressor Support in Community-Acquired Pneumonia. CLIN INFECT DIS. 47, 375-384 (2008). )

24. World Health Organisation. WHO. R\&D Blueprint - novel Coronavirus - COVID-19 Therapeutic Trial Synopsis. 2020; WHO Public health surveillance for COVID-19.

25. Therneau, T-M. \& Grambsch, P-M. Modeling Survival Data: Extending the Cox Model 2000. Springer, New York. ISBN 0-387-98784-3.

26. Blanche, P., Dartigues, J. F. \& Jacqmin-Gadda, H. Estimating and comparing time-dependent areas under receiver operating characteristic curves for censored event times with competing risks. Statist. Med. 32, 5381-5397 (2013). )

27. Mogensen, U. B., Ishwaran, H. \& Gerds, T. A. Evaluating Random Forests for Survival Analysis Using Prediction Error Curves.J. Stat. Soft. 50, (2012).

\section{Tables}

Table 1. Comparison between the different components of the risk assessment models. 


\begin{tabular}{|c|c|c|c|c|c|c|}
\hline \multirow{2}{*}{$\begin{array}{l}\text { Scores } \\
\text { Criteria }\end{array}$} & \multicolumn{2}{|l|}{ Original } & \multirow{2}{*}{$\begin{array}{l}\text { CURB } \\
65\end{array}$} & \multirow[t]{2}{*}{ CRB65 } & \multirow{2}{*}{$\begin{array}{l}\text { SMART- } \\
\text { COP }\end{array}$} & \multirow[t]{2}{*}{ qSOFA } \\
\hline & $\begin{array}{l}\text { HOME- } \\
\text { CoV }\end{array}$ & qCSI & & & & \\
\hline $\begin{array}{l}\text { Pulse oxygen saturation } \leq 94 \% \text { in } \\
\text { ambient air or need for oxygen } \\
\text { therapy }\end{array}$ & $\checkmark$ & $\checkmark$ & & & & \\
\hline \multirow{2}{*}{$\begin{array}{l}\text { Respiratory rate (different cut-off, } \\
\text { /min) }\end{array}$} & $\checkmark$ & $\checkmark$ & $\checkmark$ & $\checkmark$ & $\checkmark$ & $\checkmark$ \\
\hline & $(\geq 25)$ & $\begin{array}{l}(\leq 22 ; \\
23- \\
28 ;>28)\end{array}$ & $(\geq)$ & $(\geq 30)$ & $(\geq 25)$ & $(\geq 22)$ \\
\hline $\begin{array}{l}\text { Ability to talk without breathing }<8 \\
\text { seconds }\end{array}$ & $\checkmark$ & & & & & \\
\hline \multirow{2}{*}{$\begin{array}{l}\text { Systolic blood pressure (different cut- } \\
\text { off, mmHg) }\end{array}$} & $\checkmark$ & & $\checkmark$ & $\checkmark$ & $\checkmark$ & $\checkmark$ \\
\hline & $(\leq 90)$ & & $\begin{array}{l}(< \\
90)\end{array}$ & $(<90)$ & $(<90)$ & $\begin{array}{l}(\leq \\
100)\end{array}$ \\
\hline \multirow{2}{*}{$\begin{array}{l}\text { Heart rate (different cut-off, } \\
\text { beats/min) }\end{array}$} & $\checkmark$ & & & & $\checkmark$ & \\
\hline & $(\geq 120)$ & & & & $(\geq 125)$ & \\
\hline $\begin{array}{l}\text { Confusion or impaired } \\
\text { consciousness }\end{array}$ & $\checkmark$ & & $\checkmark$ & $\checkmark$ & $\checkmark$ & $\checkmark$ \\
\hline $\begin{array}{l}\text { Clinically significant worsening } \\
\text { within the last } 24 \text { hours }\end{array}$ & $\checkmark$ & & & & & \\
\hline \multicolumn{7}{|l|}{$\begin{array}{l}\text { Severe comorbidity }{ }^{\star} \text { AND inadequate } \\
\text { living conditions }{ }^{\dagger}\end{array}$} \\
\hline Age $>65$ years & & & $\checkmark$ & $\checkmark$ & $\checkmark$ & \\
\hline Oxygen Flow & & $\checkmark$ & & & & \\
\hline $\begin{array}{l}\text { Blood urea nitrogen }>19 \mathrm{mg} / \mathrm{dL}(>7 \\
\mathrm{mmol} / \mathrm{L})\end{array}$ & & & $\checkmark$ & & & \\
\hline Albumin $<3.5 \mathrm{~g} / \mathrm{dL}(35 \mathrm{~g} / \mathrm{L})$ & & & & & $\checkmark$ & \\
\hline $\begin{array}{l}\mathrm{PaO} \otimes<70 \mathrm{mmHg} \text {, } \mathrm{SaO} \otimes \leq 93 \% \text {, or } \\
\mathrm{PaO} \otimes / \mathrm{FiO} \otimes<333\end{array}$ & & & & & $\checkmark$ & \\
\hline PaO2/FiO2 Ratio < 250 & & & & & $\checkmark$ & \\
\hline $\begin{array}{l}\text { Multi-lobar involvement on chest } x \text { - } \\
\text { ray }\end{array}$ & & & & & $\checkmark$ & \\
\hline $\begin{array}{l}\text { * Severe chronic respiratory disease (u } \\
\text { continuous oxygen therapy), chronic } h\end{array}$ & $\begin{array}{l}\text { table as } \\
\text { it failure }\end{array}$ & $\begin{array}{l}\text { na, COP } \\
\text { IYHA } \geq\end{array}$ & $\begin{array}{l}\text { ge III } \\
\text { evere }\end{array}$ & $\begin{array}{l}\text { V, respir } \\
\text { gnitive d }\end{array}$ & $\begin{array}{l}\text { ory failure } \\
\text { order, or }\end{array}$ & \\
\hline
\end{tabular}


immunodepression (primary immunodeficiency, uncontrolled HIV, immunosuppressive drug, chemotherapy).

${ }^{\dagger}$ Inappropriate dwelling (homelessness, frail relative at home, long-term care institution), lack of support person (family member or friend), or home follow-up impossible.

\section{Table 2. Baseline Characteristics of the Patients in the different cohorts}




\begin{tabular}{|c|c|c|c|c|}
\hline \multirow[t]{3}{*}{ Characteristics } & \multicolumn{2}{|c|}{ Training cohort } & \multicolumn{2}{|c|}{ Validation cohort } \\
\hline & \multirow{2}{*}{$\begin{array}{l}\text { Total } \\
\mathrm{N}=1696 \\
(\%)\end{array}$} & \multirow{2}{*}{$\begin{array}{l}\text { Confirmed } \\
\text { COVID-19* } \\
\mathrm{N}=346(\%)\end{array}$} & \multirow{2}{*}{$\begin{array}{l}\text { Total } \\
\mathrm{N}= \\
1304 \\
(\%)\end{array}$} & \multirow{2}{*}{$\begin{array}{l}\text { Confirmed } \\
\text { COVID-19* } \\
\mathrm{N}=183(\%)\end{array}$} \\
\hline & & & & \\
\hline \multicolumn{5}{|l|}{ Demographic characteristics } \\
\hline Age - mean $\pm S D-y r$ & $\begin{array}{l}52.2 \\
\pm 19.9\end{array}$ & $55 \pm 17.9$ & $\begin{array}{l}52.5 \pm \\
18.5\end{array}$ & $53 \pm 16.3$ \\
\hline Female sex - no. (\%) & $\begin{array}{l}918 \\
(54.1)\end{array}$ & $186(53.8)$ & $\begin{array}{l}725 \\
(55.6)\end{array}$ & $114(62.3)$ \\
\hline \multicolumn{5}{|l|}{ Medical history - no. (\%) } \\
\hline Severe cognitive impairment & $18(1.1)$ & $7(2.0)$ & $\begin{array}{l}6 \\
(0.5)\end{array}$ & $2(1.1)$ \\
\hline COPD stage III/IV & $34(2.0)$ & $5(1.4)$ & $\begin{array}{l}22 \\
(1.7)\end{array}$ & $0(0)$ \\
\hline Asthma & $\begin{array}{l}176 \\
(10.4)\end{array}$ & $28(8.1)$ & $\begin{array}{l}147 \\
(11.3)\end{array}$ & $17(9.3)$ \\
\hline Severe renal disease $(\mathrm{GFR}<30 \mathrm{ml} / \mathrm{min})$ & $37(2.2)$ & $10(2.9)$ & $\begin{array}{l}28 \\
(2.1)\end{array}$ & $5(2.7)$ \\
\hline Hepatic cirrhosis child B or C & $10(0.6)$ & $1(0.3)$ & $\begin{array}{l}7 \\
(0.5)\end{array}$ & $3(1.6)$ \\
\hline Chronic cardiac failure NYHA III/IV & $24(1.4)$ & $1(0.3)$ & $\begin{array}{l}18 \\
(1.4)\end{array}$ & $6(3.3)$ \\
\hline Hypertension & $\begin{array}{l}518 \\
(30.5)\end{array}$ & $135(39.0)$ & $\begin{array}{l}351 \\
(26.9)\end{array}$ & $53(29.0)$ \\
\hline Diabetes & $\begin{array}{l}221 \\
(13.0)\end{array}$ & $64(18.5)$ & $\begin{array}{l}141 \\
(10.8)\end{array}$ & $28(15.3)$ \\
\hline History of thromboembolism & $94(5.5)$ & $13(3.8)$ & $\begin{array}{l}68 \\
(5.2)\end{array}$ & $10(5.5)$ \\
\hline Cancer history or active cancer & $\begin{array}{l}159 \\
(9.4)\end{array}$ & $35(10.1)$ & $\begin{array}{l}115 \\
(8.8)\end{array}$ & $19(10.4)$ \\
\hline Immune deficiency and HIV & $55(3.2)$ & $14(4.0)$ & $\begin{array}{l}33 \\
(2.5)\end{array}$ & $11(6.0)$ \\
\hline \multicolumn{5}{|l|}{ Signs and symptoms - no. (\%) } \\
\hline Anosmia, ageusia, dysgeusia & $\begin{array}{l}400 \\
(23.6)\end{array}$ & $112(32.4)$ & $\begin{array}{l}243 \\
(18.6)\end{array}$ & 47 (25.7) \\
\hline
\end{tabular}




\begin{tabular}{|c|c|c|c|c|}
\hline Cough & $\begin{array}{l}1127 \\
(66.5)\end{array}$ & $271(78.3)$ & $\begin{array}{l}853 \\
(65.4)\end{array}$ & $117(63.9)$ \\
\hline Dyspnea & $\begin{array}{l}1094 \\
(64.5)\end{array}$ & $244(70.5)$ & $\begin{array}{l}769 \\
(59.0)\end{array}$ & $97(53.0)$ \\
\hline Diarrhea & $\begin{array}{l}445 \\
(26.2)\end{array}$ & $81(23.4)$ & $\begin{array}{l}350 \\
(26.8)\end{array}$ & $38(20.8)$ \\
\hline Chest pain & $\begin{array}{l}592 \\
(34.9)\end{array}$ & $82(23.7)$ & $\begin{array}{l}463 \\
(35.5)\end{array}$ & $57(31.1)$ \\
\hline Confusion, impaired alertness & $91(5.4)$ & $35(10.1)$ & $\begin{array}{l}44 \\
(3.4)\end{array}$ & $8(4.4)$ \\
\hline Worsening in the last 24 hours & $\begin{array}{l}842 \\
(49.6)\end{array}$ & $203(58.7)$ & $\begin{array}{l}515 \\
(39.5)\end{array}$ & $77(42.1)$ \\
\hline Heart rate $\geq 120$ beats $/$ min & $88(5.2)$ & $23(6.7)$ & $\begin{array}{l}76 \\
(5.8)\end{array}$ & $9(4.9)$ \\
\hline Systolic blood pressure $<90 \mathrm{mmHg}$ & $12(0.7)$ & $3(0.9)$ & $\begin{array}{l}7 \\
(0.5)\end{array}$ & $2(1.1)$ \\
\hline Body Mass Index $\geq 30 \mathrm{~kg} / \mathrm{m}^{2}$ & $\begin{array}{l}230 \\
(13.6)\end{array}$ & $57(16.5)$ & $\begin{array}{l}197 \\
(15.1)\end{array}$ & $32(17.5)$ \\
\hline $\begin{array}{l}\text { Pulse oxygen saturation } \leq 94 \% \text { in ambient air } \\
\text { or necessity of oxygen therapy }\end{array}$ & $\begin{array}{l}381 \\
(22.5)\end{array}$ & $121(35.0)$ & $\begin{array}{l}326 \\
(25.0)\end{array}$ & $42(23.0)$ \\
\hline Respiratory rate $\geq 25 / \mathrm{min}$ & $\begin{array}{l}302 \\
(17.8)\end{array}$ & $55(15.9)$ & $\begin{array}{l}184 \\
(14.1)\end{array}$ & $36(19.7)$ \\
\hline $\begin{array}{l}\text { Ability to speak or count without resuming } \\
\text { breathing }<8 \text { seconds }\end{array}$ & $\begin{array}{l}206 \\
(12.1)\end{array}$ & $38(11.0)$ & $\begin{array}{l}93 \\
(7.1)\end{array}$ & $21(11.5)$ \\
\hline \multicolumn{5}{|l|}{ COVID-19 status } \\
\hline Typical COVID-19 lesion on CT scan & $\begin{array}{l}341 \\
(20.1)\end{array}$ & $182(52.6)$ & $\begin{array}{l}240 \\
(18.4)\end{array}$ & $50(27.3)$ \\
\hline Adverse evolution within the 7 days & $65(3.8)$ & $41(11.8)$ & $\begin{array}{l}22 \\
(1.7)\end{array}$ & $9(4.9)$ \\
\hline Requiring non-invasive ventilation & $18(1.1)$ & $12(3.5)$ & $\begin{array}{l}10 \\
(0.8)\end{array}$ & $5(2.7)$ \\
\hline Requiring mechanical ventilation & $15(0.9)$ & $11(3.2)$ & $\begin{array}{l}4 \\
(0.3)\end{array}$ & $2(1.1)$ \\
\hline Death (all causes) & $32(1.9)$ & $18(5.2)$ & $\begin{array}{l}8 \\
(0.9)\end{array}$ & $2(1.1)$ \\
\hline
\end{tabular}


Reverse Transcriptase Polymerase Chain Reaction; CT-Scan: Computerized Tomography scanner.

* Confirmed SARS-CoV-2 infection by Reverse Transcriptase-Polymerase Chain Reaction.

Table 3. Revised HOME-CoV rule.

\section{The presence of one or more criteria corresponds to a patient at risk of pejorative evolution Points} and should lead the physician to consider hospitalization:

Age $>65$ years

1

Pulse oxygen saturation $\leq 94 \%$ in ambient air

1

Respiratory rate $\geq 25 / \mathrm{min}$

1

Ability to talk without breathing $<8 \mathrm{sec}$

1

Confusion or impaired consciousness

Clinically significant worsening within the last 24 hours

Inadequate living conditions ${ }^{\dagger}$

${ }^{+}$Inappropriate dwelling (homelessness, frail relative at home, long-term care institution), lack of support person (family member or friend), or home follow-up impossible.

Table 4. Performance scores in the training and the validation cohorts.

\begin{tabular}{|c|c|c|c|c|c|c|}
\hline \multirow{3}{*}{$\begin{array}{l}\text { Training Cohort } \\
(n=1696)\end{array}$} & \multicolumn{2}{|l|}{ At D2 } & \multicolumn{2}{|l|}{ At D7 } & \multicolumn{2}{|l|}{ At D28 } \\
\hline & AU-ROC & Brier & AU-ROC & Brier & AU-ROC & Brier \\
\hline & $\begin{array}{l}(95 \% \\
\text { bootstrap Cl) }\end{array}$ & & $\begin{array}{l}(95 \% \\
\text { bootstrap Cl) }\end{array}$ & & $\begin{array}{l}(95 \% \\
\text { bootstrap Cl) }\end{array}$ & \\
\hline $\begin{array}{l}\text { Revised HOME- } \\
\text { CoV }\end{array}$ & $\begin{array}{l}89.3(86.9- \\
91.7)\end{array}$ & 0.036 & $\begin{array}{l}87.6(84.7- \\
90.6)\end{array}$ & 0.045 & $\begin{array}{l}86.7(83.5- \\
89.9)\end{array}$ & 0.047 \\
\hline $\begin{array}{l}\text { Original HOME- } \\
\text { CoV }\end{array}$ & $\begin{array}{l}81.4(76.6- \\
86.2)\end{array}$ & 0.043 & $\begin{array}{l}80.9(76.3- \\
85.6)\end{array}$ & 0.048 & $\begin{array}{l}80.7(76.2- \\
85.1)\end{array}$ & 0.049 \\
\hline qCSI & $\begin{array}{l}76.9(71.6- \\
82.1)\end{array}$ & 0.038 & $\begin{array}{l}75.5(70.6- \\
80.5)\end{array}$ & 0.044 & $\begin{array}{l}74.7(69.7- \\
79.7)\end{array}$ & 0.045 \\
\hline qSOFA & $\begin{array}{l}75.6(70.3- \\
80.8)\end{array}$ & 0.042 & $\begin{array}{l}74.4(69.4- \\
79.3)\end{array}$ & 0.049 & $\begin{array}{l}73.0(68.1- \\
78.0)\end{array}$ & 0.050 \\
\hline CRB65 & $\begin{array}{l}83.9(79.9- \\
88.0)\end{array}$ & 0.038 & $\begin{array}{l}78.6(73.7- \\
83.5)\end{array}$ & 0.044 & $\begin{array}{l}77.8(72.9- \\
82.6)\end{array}$ & 0.045 \\
\hline
\end{tabular}




\begin{tabular}{|c|c|c|c|c|c|c|}
\hline \multirow{3}{*}{$\begin{array}{l}\text { Validation } \\
\text { Cohort } \\
\text { All patients } \\
(n=1304)\end{array}$} & \multicolumn{2}{|l|}{ At D2 } & \multicolumn{2}{|l|}{ At D7 } & \multicolumn{2}{|l|}{ At D28 } \\
\hline & & Brier & AU-ROC & Brier & AU-ROC & Brier \\
\hline & \multicolumn{2}{|l|}{$\begin{array}{l}\text { (95\% } \\
\text { bootstrap Cl) }\end{array}$} & \multicolumn{2}{|l|}{$\begin{array}{l}\text { (95\% } \\
\text { bootstrap Cl) }\end{array}$} & \multicolumn{2}{|l|}{$\begin{array}{l}\text { (95\% } \\
\text { bootstrap Cl) }\end{array}$} \\
\hline $\begin{array}{l}\text { Revised HOME- } \\
\text { CoV }\end{array}$ & $\begin{array}{l}86.5(81.1- \\
91.9)\end{array}$ & 0.018 & $\begin{array}{l}85.8(80.6- \\
91.0)\end{array}$ & 0.019 & $\begin{array}{l}85.8(80.6- \\
91.0)\end{array}$ & 0.019 \\
\hline $\begin{array}{l}\text { Original HOME- } \\
\text { CoV }\end{array}$ & $\begin{array}{l}85.1(78.9- \\
91.4)\end{array}$ & 0.021 & $\begin{array}{l}84.2(78.4- \\
90.0)\end{array}$ & 0.022 & $\begin{array}{l}84.2(78.4- \\
90.0)\end{array}$ & 0.022 \\
\hline qCSI & $\begin{array}{l}79.0(70.8- \\
87.2)\end{array}$ & 0.021 & $\begin{array}{l}78.7(70.9- \\
86.5)\end{array}$ & 0.022 & $\begin{array}{l}78.7(70.9- \\
86.5)\end{array}$ & 0.022 \\
\hline qSOFA & $\begin{array}{l}70.4(61.6- \\
79.31\end{array}$ & 0.021 & $\begin{array}{l}71.9(64.00- \\
79.7)\end{array}$ & 0.023 & $\begin{array}{l}71.9(64.0- \\
79.7)\end{array}$ & 0.023 \\
\hline CRB65 & $\begin{array}{l}77.3(68.8- \\
85.8)\end{array}$ & 0.021 & $\begin{array}{l}77.6(69.5- \\
85.8)\end{array}$ & 0.022 & $\begin{array}{l}77.6(69.5- \\
85.8)\end{array}$ & 0.022 \\
\hline $\begin{array}{l}\text { Validation } \\
\text { Cohort }\end{array}$ & \multicolumn{2}{|l|}{ At D2 } & \multicolumn{2}{|l|}{ At D7 } & \multicolumn{2}{|l|}{ At D28 } \\
\hline \multirow{2}{*}{$\begin{array}{l}\text { Confirmed } \\
\text { COVID-19* } \\
(n=183)\end{array}$} & AU-ROC & \multirow[t]{2}{*}{$\begin{array}{l}\text { Brier } \\
\text { score }\end{array}$} & AU-ROC & \multirow{2}{*}{$\begin{array}{l}\text { Brier } \\
\text { score }\end{array}$} & AU-ROC & \multirow{2}{*}{$\begin{array}{l}\text { Brier } \\
\text { score }\end{array}$} \\
\hline & $\begin{array}{l}\text { (95\% } \\
\text { bootstrap Cl) }\end{array}$ & & $\begin{array}{l}\text { (95\% } \\
\text { bootstrap Cl) }\end{array}$ & & $\begin{array}{l}\text { (95\% } \\
\text { bootstrap Cl) }\end{array}$ & \\
\hline $\begin{array}{l}\text { Revised HOME- } \\
\text { CoV }\end{array}$ & $\begin{array}{l}87.8(81.2- \\
94.4)\end{array}$ & 0.039 & $\begin{array}{l}85.5(76.8- \\
94.1)\end{array}$ & 0.047 & $\begin{array}{l}85.5(76.8- \\
94.1)\end{array}$ & 0.030 \\
\hline $\begin{array}{l}\text { Original HOME- } \\
\text { CoV }\end{array}$ & $\begin{array}{l}85.2(76.4- \\
93.9)\end{array}$ & 0.050 & $\begin{array}{l}83.4(75.0- \\
91.9)\end{array}$ & 0.062 & $\begin{array}{l}83.4(75.0- \\
91.9)\end{array}$ & 0.046 \\
\hline qCSI & $\begin{array}{l}73.6(56.2- \\
91.1)\end{array}$ & 0.045 & $\begin{array}{l}74.1(58.4- \\
89.9)\end{array}$ & 0.042 & $\begin{array}{l}74.1(58.4- \\
89.9)\end{array}$ & 0.051 \\
\hline qSOFA & $\begin{array}{l}69.9(51.8- \\
88.0)\end{array}$ & 0.055 & $\begin{array}{l}71.8(58.3- \\
85.3)\end{array}$ & 0.059 & $\begin{array}{l}71.8(58.3- \\
85.3)\end{array}$ & 0.053 \\
\hline CRB-65 & $\begin{array}{l}76.2(63.2- \\
89.3)\end{array}$ & 0.051 & $\begin{array}{l}75.5(62.2- \\
88.7)\end{array}$ & 0.059 & $\begin{array}{l}75.4(62.2- \\
88.7)\end{array}$ & 0.053 \\
\hline
\end{tabular}

Table 5. Distribution of the revised HOME-CoV score among patients according to different threshold in training and validation cohorts. 


\begin{tabular}{|c|c|c|c|c|}
\hline All patients $(\mathrm{N}=3000)$ & \multicolumn{2}{|c|}{ Training cohort $(n=1696)$} & Validation cohort $(n=1304)$ & \\
\hline \multirow[t]{2}{*}{ Defined threshold } & $<2$ & $>3$ & $<2$ & $>3$ \\
\hline & $\begin{array}{l}(n=1092 \\
64.4 \%)\end{array}$ & $(n=158,9.3 \%)$ & $(n=949,72.7 \%)$ & $(n=86,6.6 \%)$ \\
\hline \multicolumn{5}{|l|}{ Performances (95\% Cl) } \\
\hline Sensibility & $0.96(0.89-0.99)$ & $\begin{array}{l}0.44(0.34- \\
0.55)\end{array}$ & $\begin{array}{l}0.84(0.66- \\
0.95)\end{array}$ & $0.39(0.22-0.58)$ \\
\hline Specificity & $0.65(0.63-0.68)$ & $\begin{array}{l}0.93(0.92- \\
0.94)\end{array}$ & $\begin{array}{l}0.71(0.68- \\
0.73)\end{array}$ & $0.94(0.93-0.96)$ \\
\hline $\begin{array}{l}\text { Negative predictive } \\
\text { value }\end{array}$ & $1.00(0.99-1.00)$ & $\begin{array}{l}0.97(0.96- \\
0.98)\end{array}$ & $\begin{array}{l}0.99(0.99- \\
1.00)\end{array}$ & $0.99(0.98-0.99)$ \\
\hline Positive predictive value & $0.13(0.11-0.16)$ & $\begin{array}{l}0.26(0.19- \\
0.34)\end{array}$ & $\begin{array}{l}0.06(0.04- \\
0.09)\end{array}$ & $0.14(0.07-0.23)$ \\
\hline Negative likelihood ratio & $0.07(0.03-0.17)$ & $\begin{array}{l}0.60(0.50- \\
0.72)\end{array}$ & $\begin{array}{l}0.23(0.10- \\
0.51)\end{array}$ & $0.65(0.49-0.86)$ \\
\hline Positive likelihood ratio & $2.77(2.56-2.99)$ & $\begin{array}{l}6.29(4.72- \\
8.39)\end{array}$ & $\begin{array}{l}2.84(2.39- \\
3.39)\end{array}$ & $\begin{array}{l}7.00(4.27- \\
11.49)\end{array}$ \\
\hline $\begin{array}{l}\text { Confirmed COVID-19* } \\
(n=183)\end{array}$ & \multicolumn{3}{|c|}{ Training cohort $(n=346)$} & \\
\hline \multirow[t]{2}{*}{ Defined threshold } & $<2$ & \multirow{2}{*}{$\begin{array}{l}>3 \\
(n=31,9.0 \%)\end{array}$} & $<2$ & $>3$ \\
\hline & $(n=199,57.5 \%)$ & & $(n=114,62.3 \%)$ & $(n=11,6.0 \%)$ \\
\hline \multicolumn{5}{|l|}{ Performances (95\% Cl) } \\
\hline Sensibility & $0.96(0.87-1.00)$ & $\begin{array}{l}0.46(0.31- \\
0.62)\end{array}$ & $\begin{array}{l}0.91(0.59- \\
1.00)\end{array}$ & $0.56(0.34-0.72)$ \\
\hline Specificity & $0.60(0.54-0.65)$ & $\begin{array}{l}0.94(0.90- \\
0.96)\end{array}$ & $\begin{array}{l}0.66(0.58- \\
0.73)\end{array}$ & $0.96(0.92-0.98)$ \\
\hline $\begin{array}{l}\text { Negative predictive } \\
\text { value }\end{array}$ & $0.99(0.96-1.00)$ & $\begin{array}{l}0.96(0.95- \\
0.99)\end{array}$ & $\begin{array}{l}0.99(0.95- \\
1.00)\end{array}$ & $0.99(0.95-1.00)$ \\
\hline Positive predictive value & $0.28(0.22-0.35)$ & $\begin{array}{l}0.34(0.11- \\
0.42)\end{array}$ & $\begin{array}{l}0.14(0.07- \\
0.25)\end{array}$ & $0.13(0.05-0.32)$ \\
\hline Negative likelihood ratio & $\begin{array}{l}0.06(0.02- \\
0.24)\end{array}$ & $\begin{array}{l}0.58(0.45- \\
0.74)\end{array}$ & $\begin{array}{l}0.99(0.95- \\
1.00)\end{array}$ & $0.58(0.41-0.80)$ \\
\hline Positive likelihood ratio & $2.38(2.07-2.74)$ & $\begin{array}{l}7.42(3.82- \\
8.45)\end{array}$ & $\begin{array}{l}2.65(2.01- \\
3.50)\end{array}$ & $\begin{array}{l}7.96(5.01- \\
14.21)\end{array}$ \\
\hline
\end{tabular}




\section{Figures}
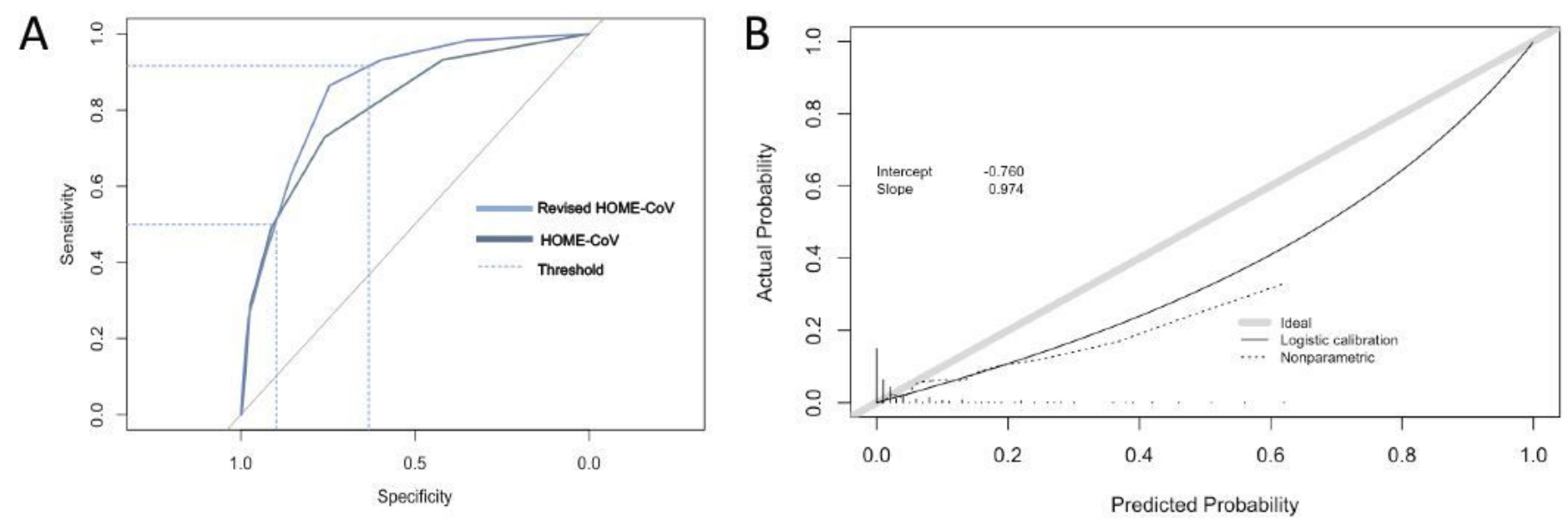

\section{Figure 1}

Receiver operating characteristic curve for revised HOME-CoV and the original HOME-CoV scores $(\mathrm{A})$ and calibration plots for the revised HOME-CoV score in the validation cohort (B). For calibration plots (B), the grey zone represents the ideal distribution. The distributions of predicted probabilities are shown at the bottom of the graphs.

\section{Supplementary Files}

This is a list of supplementary files associated with this preprint. Click to download.

- Supplementarymaterial.pdf 